\title{
História e PROGResSo em EMANUel Kant
}

\author{
[PROGRESS AND HISTORY IN IMMANUEL KANT]
}

\section{Antonio Djalma Braga Junior *} Universidade Positivo, Brasil

\begin{abstract}
Resumo: A obra IaG de Kant é uma referência para os estudos sobre a história porque nos apresenta uma concepção especulativa dessa disciplina. Essa obra também nos aponta o pano de fundo moral que essa concepção especulativa da história pretende demonstrar. Por isso, podemos analisar a filosofia da história de Kant como um complemento de sua filosofia moral. A pergunta que deve ser feita diante de tal posicionamento é exatamente essa: como o filósofo consegue demonstrar estes resultados? A resposta a isso nos leva à tese do progresso na filosofia da história de Kant, mas que de certa forma é bastante comum no século XVIII: a história só teria sentido se pudesse ser compreendida a partir da noção de um progresso contínuo. Kant procura defender a possibilidade, no campo da história, de que a Natureza ou a Providência esteja executando um plano a longo prazo que trará benefícios à humanidade enquanto espécie, ainda que exija o sacrifício do bem-estar da mesma enquanto indivíduo. Kant demonstra que podemos compreender com a razão, e sua capacidade inventiva, que a humanidade está em pleno desenvolvimento ao longo do curso da história, ainda que não possamos ver o desenvolvimento no indivíduo, mas apenas na espécie.
\end{abstract}

Palavras-chave: Filosofia da História; Progresso; Liberdade; Natureza; Providência; Filosofia Moral
ABSTRACT: Kant's IaG is a reference for history studies because it gives us a speculative conception of this discipline. This work also points us to the moral background that this speculative conception of history intends to demonstrate. Therefore, we can analyze Kant's philosophy of history as a complement to his moral philosophy. The question that must be asked before such a position is exactly this: how can the philosopher demonstrate these results? The answer to this leads us to the thesis of progress in Kant's philosophy of history, but which is somewhat common in the eighteenth century: the History would only make sense if it could be understood from the notion of continuous progress. Kant seeks to defend the possibility, in the field of history, that Nature or Providence is executing a long-term plan that will bring benefits to humanity as a species, even though it requires the sacrifice of its welfare as an individual. Kant demonstrates that we can understand with reason, and its inventive capacity, that humanity is in full development throughout the course of history, even though we cannot see development in the individual but only in the species.

KEYWORDS: Philosophy of history; Progress; Freedom; Nature; Providence; Moral Philosophy

\section{A expressão filosofia da história poder ser entendida no sentido de designar A uma investigação crítica do pensamento histórico e seus processos. Desse} modo, ela é parte do ramo da filosofia conhecido como teoria do conhecimento e tem como objetivo produzir uma interpretação do curso real dos acontecimentos, demonstrando que há uma inteligibilidade especial como fio condutor destes.

* Doutor em Filosofia pela Universidade Federal do Paraná - UFPR. Professor de Filosofia da Universidade Positivo. Coordenador do Grupo de Pesquisas do CNPQ "LIFIDI - Liberdade, Filosofia e Direito". E-mail: antonio.djalma@hotmail.com 
Na concepção de W. H. Walsh (1978, p. 116) a história, aos olhos dos filósofos do século XIX, era considerada como um problema filosófico porque, apesar da característica aparentemente caótica dos fatos no curso do tempo, não se podia aceitar que não existiria algo por trás guiando esses acontecimentos de maneira inteligível. Era preciso admitir que algo (ou alguém) estaria conduzindo inteligivelmente o curso da história, até porque, se não existe uma configuração racional na sequência de acontecimentos históricos, "então, como habitualmente se diz, os sofrimentos e desastres relatados pelos historiadores são 'gratuitos' e 'absurdos', e há um forte elemento na natureza humana que se revolta contra a aceitação dessa conclusão".

Kant não foi o primeiro a desenvolver uma filosofia da história, da mesma forma não se pode afirmar que ele teve um interesse autêntico pela história em si, ou que pretendia em seu sistema Crítico abordar tal tema, até porque, no geral, sua perspectiva era sempre curiosamente anti-histórica: o interesse de Kant pela história era genuinamente um produto da Aufklärung, frutos do seu tempo e, em grande medida, das discussões com Herder (Cf. WALSH, 1978, p. 117).

Todavia, isso não quer dizer que o que ele produziu sobre a filosofia da história não tenha o mesmo rigor do sistema Crítico, ou que não esteja alinhado a ele. Ao contrário, o que pretendemos nesta tese é demonstrar que seus escritos sobre a história ajudam a preencher lacunas que não foram detalhadamente trabalhadas nas obras Críticas.

Assim, veremos nos próximos tópicos como, primeiramente, Jacques Bossuet e Giambattista Vico começam a pensar em uma filosofia da história a partir do conceito de Providência, para, em seguida, seguirmos com nossa análise sobre a contribuição de Kant.

\section{HistóRIA-PORVIDÊNCIA ANTES de KANT}

Uma das primeiras filosofias da história que surge na modernidade foi aquela desenvolvida por Jacques Bossuet. Em sua obra Discurso da história universal, publicada em 1681, ele desenvolve uma série de lições sobre a filosofia da história procurando defender que a história é fruto da vontade divina e que a tarefa do historiador é apenas descrever como acontecem esses desígnios divinos, ou melhor, esse desígnio providencial. Ele chama a atenção para o fato de que a religião e a política são os pontos principais nos quais as coisas humanas estão centradas e compreender isso de um modo organizado sequencialmente é compreender o fio condutor de todos os negócios do universo (Cf. DOSSE, 2012, p. 230).

Diante dessa concepção de história aliado ao conceito de Providência, Bossuet escreve o Discurso descrevendo os acontecimentos históricos desde os assírios e os babilônios até o reinado de Carlos Magno com uma característica marcadamente divina e providencial. Da mesma forma, defende que a religião é sempre a mesma desde os primórdios, pois seria Deus o único autor e salvador da humanidade e os textos sagrados não devem ser banalizados ou considerados como textos meramente humanos. Por fim, Bossuet também narra a história dos impérios a partir de uma concepção de sucessão regulada pela Providência, como uma verdadeira Teodicéia, cabendo "à realidade curvar-se ao esquema providencial e, quando ela parece contradizer a lógica, nossa percepção é que deve ser questionada, pois nossas paixões nos desorientam" (DOSSE, 2012, p. 231).

Giambattista Vico é outro que procura analisar a história sob a ótica da Providência. Tendo vivido na Itália no início do século XVIII, participa da vida literária 
de sua época mantendo-se em um certo isolamento em grande parte por não aceitar pensar a história dos homens desconectada da história divina. Diante disso, ele pretende unificar estas duas (história profana e sagrada) a partir da ideia da Providência. Esse conceito é importante para ele porque permite pensar a história sagrada de um modo racional e moral ao mesmo tempo, ao passo que a história profana seria um misto de desordem, caos, violência e injustiça. Desse modo, ele procura alcançar a cultura do seu tempo a partir de sua própria história, pois acredita que as mais variadas dimensões das sociedades só poderão ser compreendidas cada qual em sua própria época.

Vico mantém-se em constante tensão entre a preocupação de restituir a
particularidade de cada sociedade, que só o procedimento histórico pode
discernir, e a vontade de unificação da pluralidade no âmbito da Providência, que
continua sendo o horizonte de sua pesquisa, como indica o título de seu livro
Princípios de uma ciência nova relativa à natureza comum das nações publicados
em 1725 (DOSSE, 2012, p. 222).

Por isso essa noção de Providência ganha um aspecto central no pensamento de Vico, que vê o desenrolar da história como a sucessão de três eras da humanidade, a era dos deuses, a era dos heróis e a dos homens: "à era das sociedades patriarcais, marcadas pela onipresença dos deuses, seguem-se as sociedades aristocráticas, caracterizadas pela presença dos heróis, e, por fim, surge a sociedade dos homens, que é também a da ciência e da filosofia" (DOSSE, 2012, p. 233). Todas essas eras passam por um esquema histórico onde a Providência mantém sempre a garantia do sucesso emancipatório e da realização progressiva de cada etapa, fazendo com que o homem saia da animalidade e passe à sua maturidade.

Da mesma forma, essa Providência pode ser pensada a partir do que Vico chama de lei dos ricorsi, que é, em suma, a ideia de que a humanidade sempre retorna a suas origens, indicando que a história não progride de maneira linear, mas como uma espécie de espiral com o auxílio da Providência.

\section{A Filosofia da hiStóRIa ESPECUlativa EM KaNT}

No que diz respeito a Kant, quando falamos de uma filosofia da história, temos que dirigir nosso olhar especialmente ao seu artigo Ideia de uma História Universal de um ponto de vista cosmopolita ( $\mathrm{IaG}, \mathrm{AA} 08)$.

A obra IaG é uma referência para os estudos sobre a história porque nos apresenta uma concepção especulativa dessa disciplina. Kant, com toda sua modéstia, reconhece nessa obra suas limitações teóricas quanto ao conhecimento de todos os fatos históricos da humanidade (do ponto de vista teórico é impossível conhecer todos os fatos e acontecimentos), justamente por isso que esboçou uma ideia de história universal. Da mesma forma, a obra IaG também nos aponta o pano de fundo moral que essa concepção especulativa da história pretende demonstrar. Por isso, podemos analisar a filosofia da história de Kant como um complemento de sua filosofia moral. Walsh é enfático em defender essa perspectiva da história aliada à moral em Kant:

Com ele [Kant], pelo menos a filosofia da história era um complemento da filosofia moral. Na verdade, não há muita coisa para sugerir que ele teria tratado da história, não fossem as questões morais que ela parecia suscitar. (...) Se a história é o que aparenta ser, uma fé na providência divina está afastada; não obstante, essa fé, ou algo semelhante (...), é essencial para que levemos uma vida moral. A tarefa do filósofo em relação à história é, portanto, mostrar que, apesar das primeiras aparências, a história é um processo racional no duplo sentido de 
um processo que se desenrola num plano inteligível e que tende para uma meta que a razão moral pode aprovar. (WALSH, 1978, p. 117-118).

Todavia, a pergunta que deve ser feita diante de tal posicionamento é exatamente essa: como o filósofo consegue demonstrar estes resultados? A resposta a isso nos leva à tese do progresso na filosofia da história de Kant, mas que de certa forma é bastante comum no século XVIII: a história só teria sentido se pudesse ser compreendida a partir da noção de um progresso contínuo. Essa noção de progresso não é vista de um modo meramente linear (em linha reta) e não pode ser percebido se o virmos a partir dos indivíduos singulares. Se olharmos sob esta ótica do indivíduo, a história parecerá apenas um amontoado caótico de acontecimentos sem relação uns com os outros e sem nenhuma ordenação racional. Ao contrário, só podemos perceber essa noção de progresso se olharmos o desenvolvimento da espécie como um todo: "Aquilo que, do ponto de vista do indivíduo, parece 'incoerente e sem lei', pode revelar-se ordenado e inteligível quando visto do ângulo de toda a espécie” (WALSH, 1978, p. 118).

Assim, Kant procura defender a possibilidade, no campo da história, de que a Natureza ou a Providência esteja executando um plano a longo prazo que trará benefícios à humanidade enquanto espécie, ainda que exija o sacrifício do bem-estar da mesma enquanto indivíduo. O fato é que tal ideia, para Kant, não apenas é possível de pensar, como também é um dever aceitarmos tal ideia, pois uma vez que o homem tem em si certas disposições e potencialidades, seria contrário à razão pensar que a Natureza colocaria em nós tais disposições por acaso, em vão, ou que tais disposições postas ali nunca pudessem serem desenvolvidas. Mas, ao contrário, podemos compreender com a razão, e sua capacidade inventiva, que ela está em pleno desenvolvimento ao longo do curso da história, ainda que não possamos ver o desenvolvimento no indivíduo, mas apenas na espécie: "devemos portanto imaginar que a Natureza tem certos recursos para fazer com que essas potencialidades se desenvolvam por um longo período de tempo, de modo a se realizarem no que concerne à espécie, embora não no caso de todos os seus membros individuais" (WALSH, 1978, p. 119).

Essa é uma das teses fundamentais que aparece na obra IaG de Kant, a tese da sociabilidade insociável do homem. Veremos isso com maior cuidado e atenção no tópico seguinte, por ora, precisamos compreender é que essa característica própria da natureza humana, característica esta vista de um modo negativo, é utilizada pela Natureza para conduzir-nos do estado de barbárie para o estado de civilização.

Com efeito, vemos alguns sentidos de passagem que nos interessam para nossa tese. Um primeiro sentido de passagem é a que consiste na passagem do estado de natureza para o estado civil. Kant não se refere aqui a toda e qualquer sociedade civil, mas aquela que não seja despótica ou totalitária e que, portanto, impede o uso da liberdade, mas, ao contrário, uma sociedade civil que permita o antagonismo da sociabilidade insociável de um modo mais pleno possível e que permita a liberdade de cada indivíduo coexistir simultaneamente sem que haja prejuízos a ela (liberdade). Todavia, não basta que essa sociedade civil consiga tal realização de maneira isolada, é necessário que tal ideal seja elevado a um plano internacional. Decorre daí a conclusão de que o objetivo final da Natureza no curso da história é o estabelecimento de uma confederação de sociedades civis organizadas com autoridade sobre todos os seus membros, com vistas a garantir a liberdade de todos. Nesse sentido, a história da espécie humana é a história de um plano secreto que a Natureza criou para desenvolver uma constituição política perfeita que possa garantir que essa mesma Natureza se realize plenamente na humanidade. 


\section{OS SENTIDOS DE HISTÓRIA E A TESE DO PROGRESSO EM KANT}

Frederick Rauscher procura demonstrar, em seu artigo The Nature of "Wholly Empirical" History (2001), que existem duas formas de entender a tese do progresso no curso da história: uma defende que a ideia de progresso na história é um produto a priori da faculdade da razão e a outra diz que, se estudarmos a história do seu ponto de vista empírico, presumivelmente não será produto da razão. Essas duas abordagens dependem da separação da faculdade constitutiva do entendimento da faculdade reguladora não constitutiva da razão.

Rauscher vai defender que essa separação é problemática quando é aplicada aos estudos da história e sugere que essa complicação se mantém para as outras ciências empíricas. Assim, a primeira coisa que ele procura esclarecer em seu texto é como ele entende os conceitos de história, história empírica e história filosófica ${ }^{l}$.

História é uma disciplina que procura colocar em ordem e dar um significado à coleção aparentemente caótica de fatos sobre o passado humano. Essa concepção de história contrasta com a opinião de que essa ciência estaria preocupada apenas com a coleta de fatos sobre o passado.

História empírica é o estudo histórico que não recorre a ideias da reflexão filosófica da razão. Isso deve excluir a pretensão da existência de uma ideia a priori de progresso (que é fruto de uma ideia da razão).

História filosófica é o que Kant faz em seus ensaios sobre a filosofia da história: uso de ideias a priori específicas da razão para encontrar significados e padrões no passado.

No caso da tese de um progresso na história, um historiador empírico teria que determinar a posteriori tal progresso. Em vez disso, um filósofo da história (história filosófica) teria de analisar a história aplicando uma ideia filosófica de progresso na matéria prima de seu estudo.

O texto Ideia de uma História Universal de um Ponto de Vista Cosmopolita, publicado por Kant em 1784, faz uma clara distinção entre uma história empírica e o uso que que se pode fazer de uma ideia da razão como uma história filosófica no seu parágrafo final:

Seria uma incompreensão do meu propósito considerar que, com esta ideia de uma história do mundo (Weltgeschichte), que de certo modo tem um fio condutor a priori, eu quisesse excluir a elaboração da história (Historie) propriamente dita, composta apenas empiricamente; isto é somente um pensamento do que uma cabeça filosófica (que, de resto, precisaria ser muito versada em história) poderia tentar ainda de outro ponto de vista. (KANT, IaG AA 08: 30; 29-34).

Kant afirma neste trecho da $\mathrm{IaG}$ que seria um mal-entendido interpretar que, com sua história filosófica, ele quisesse tomar o lugar da história empírica. Essa ideia é apenas o reflexo do que uma mente filosófica pode tentar fazer a partir de uma outra perspectiva (que não a empírica).

É preciso destacar, portanto, que existem dois tipos de história em Kant: uma Weltgeschichte (ou allgemeine Geschichte) e uma Historie. Joel Thiago Klein nos alerta para o problema que esses termos em alemão podem causar pela questão de que na língua portuguesa ambos são traduzidos apenas como história e “(...) como na maioria das vezes Kant não qualifica o substantivo 'Geschichte', (...) torna necessário considerar o contexto em que o termo é empregado" (KLEIN, 2016, p. 38).

Assim, enquanto Rauscher opta pelos termos história filosófica (philosophical history) para traduzir o termo Weltgeschichte e história empírica (empirical history) 
para traduzir o termo Historie (Cf. RAUSCHER, 2001, p. 45), Klein (2016, p. 38) prefere, para evitar ambiguidades, adotar:

(...) o termo "história universal" como significando a história filosófica construída segundo um fio condutor a priori. Já o termo "história empírica" ou simplesmente "história" é entendido aqui como significando a narrativa dos fenômenos históricos segundo uma perspectiva empírica, ou mesmo a própria ciência da historiografia.

Esclarecidas essas diferenças terminológicas, podemos analisar a argumentação que Rauscher desenvolve para explicar seu posicionamento sobre a tese do progresso na história. Ele destaca inicialmente que essa separação é um tanto problemática quando procuramos analisar essa tese, sobretudo no texto $\mathrm{IaG}$, uma vez que apenas a história filosófica nos permite fazer uso desse conceito (de progresso), pois a história empírica consiste em reivindicações de conhecimento a posteriori de um estudo empírico e a história filosófica consiste em interpretações a priori decorrentes da razão.

O que Rauscher quer demonstrar é que a história empírica, nos termos de Kant, poderia, sim, dar suporte empírico ao conceito de progresso, mas apenas se ele desdenhasse da distinção entre os dois tipos de história. Mas isso tornaria sua argumentação problemática, porque Kant sustenta que esse progresso depende das reivindicações sobre o propósito na natureza, que podem resultar apenas de uma interpretação a priori da razão. Na medida em que a noção de propósito está implicada em um estudo histórico, então, parece que tal estudo não poderia ser empírico.

Desse modo, a posição de Kant nos mostra que há um contínuo progresso da humanidade em direção à uma condição política moralmente ideal caracterizada por um republicanismo nacional que maximiza a liberdade individual, tal como, uma federação mundial internacional de nações que garante a paz internacional (Cf. KANT, IaG, AA 08: 27). No entanto, o que Rauscher quer demonstrar é que apenas as teses 1-2 e 8-9 da obra IaG dependem diretamente de reivindicações sobre o propósito da natureza, uma vez que as teses 3-7, ao contrário, são perfeitamente compatíveis com uma investigação histórica puramente empírica. Um olhar mais atento revelará que elas podem ser entendidas independentemente das outras teses e, aparentemente, como dando suporte empírico às reivindicações sobre o progresso na história.

3.1.O progresso na história na obra Ideia de uma história universal de um ponto de vista cosmopolita

Tanto a primeira como a segunda tese da $\mathrm{IaG}$ dependem de uma visão teleológica da natureza, envolvendo noções de propósito e fim:

\section{Primeira proposição}

Todas as disposições naturais de uma criatura estão destinadas a um dia se desenvolver completamente e conforme a um fim (...).

\section{Segunda proposição}

No homem (única criatura racional sobre a Terra) aquelas disposições naturais que estão voltadas para o uso de sua razão devem desenvolver-se completamente apenas na espécie e não no indivíduo. (KANT, IaG, AA 08: 18; 19-32, p. 5, grifo nosso).

Isso está em conformidade com a reivindicação que Kant oferece sobre um progresso a priori na história. Assim, as teses um e dois evitam alegações empíricas sobre a base do progresso em favor da explicação expressa em termos de propósitos $a$ 
priori da natureza.

Mas a terceira e a quarta proposição nos permite pensar que a história empírica também possa concluir que o progresso na história é real.

\section{Terceira proposição}

A natureza quis que o homem tirasse inteiramente de si tudo o que ultrapassa a ordenação mecânica de sua existência animal e que não participasse de nenhuma felicidade ou perfeição senão daquela que ele proporciona a si mesmo, livre do instinto, por meio da própria razão.

\section{Quarta proposição}

O meio de que a natureza se serve para realizar o desenvolvimento de todas as suas disposições é o antagonismo delas na sociedade, na medida em que ele se torna ao fim a causa de uma ordem regulada por leis desta sociedade. (...) Esta disposição é evidente na natureza humana. (KANT, IaG, AA 08: 19-20; 18-21; 26-28, p. 6-7, grifo nosso).

Um cientista social pode observar as ações humanas na história e concluir, com base na observação empírica, que os seres humanos necessitam, de fato, de sua razão para atender às suas necessidades (diferente dos outros animais que dependem apenas do instinto e de seu corpo, como por exemplo, as garras do leão). Embora Kant se sirva de uma linguagem teleológica na explicação dessa terceira proposição, podemos perceber que isso não seria necessário, bastaria partir da ideia de que os homens devem pensar (usar a razão) para sobreviver e concluir isso em uma investigação empírica da história.

Esse distanciamento da perspectiva teleológica pode ser visualizado mais claramente na quarta proposição, uma vez que ele argumenta que o desenvolvimento da razão acontece mediante ações egoístas dos indivíduos, que os leva a viverem em sociedade para prover suas necessidades da melhor forma possível. É o que podemos ver na famosa tese da insociável sociabilidade dos homens, nesse antagonismo entre egoísmo e cooperação social que fornece aos indivíduos o incentivo para desenvolver suas disposições naturais.

E certo que o desenvolvimento dessas disposições só pode ser compreendido na espécie como um todo e não no indivíduo. À medida que a razão se desenvolve na espécie podemos visualizar arranjos políticos cada vez mais racionais que se aproximam mais fortemente de um ideal moral, sendo que o progresso pode ser entendido, aqui, como um produto dessa sociabilidade humana perfeitamente perceptível a partir de uma investigação a posteriori da história, da perspectiva de uma história empírica, e que nada (ou pouco) possui da reivindicação teleológica a priori da razão vista nas duas primeiras proposições da IaG.

$\mathrm{Na}$ oitava proposição Kant parece confirmar essa possibilidade do progresso a partir de uma história empírica quando menciona que

O problema está em saber se a experiência revela algo de um tal curso do propósito da natureza. Digo que muito pouco, pois este ciclo parece exigir tanto tempo para cumprir-se que, deste ponto de vista, a pequena parte que a humanidade percorreu permite determinar somente de maneira muito incerta a forma de sua trajetória e a relação das partes como o todo, e o mesmo ocorre se quisermos determinar, a partir das observações do céu feitas até aqui, o curso do nosso sol junto como todo o cortejo de seus satélites no grande sistema de estrelas fixas - entretanto o princípio geral da constituição sistemática da estrutura do 
mundo e o pouco que se observou bastam para concluir com segurança a respeito da realidade de um tal ciclo (KANT, IaG, AA 08: 27; 11-22, p. 17).

Ao recorrer a uma analogia com o caminho dos planetas no céu, Kant quer nos mostrar que, da mesma forma que é possível determinar as órbitas dos planetas apenas mediante a observação empírica, o mesmo acontece ao fazermos as poucas observações na história do desenvolvimento da sociedade. Com efeito, essa analogia sugere que o progresso na história pode ser considerado uma reivindicação empiricamente detectável, da mesma forma que a generalização do caminho das observações de um planeta também pode fornecer uma afirmação empiricamente detectável sobre sua órbita (Cf. RAUSCHER, 2001, p. 47).

Rauscher está certo de que essa conclusão é problemática e apresenta algumas considerações sobre a possibilidade real do progresso e sobre a distinção entre a história empírica e a história filosófica para provar isso. filosófica

3.2.A possibilidade real do progresso na História empírica e na História

O primeiro ponto analisado por Rauscher sobre essa possibilidade real do progresso na história diz respeito ao tema da necessidade e contingência que está presente nessas duas concepções de história: a ideia a priori, oriunda da razão, é sempre necessária, enquanto o fato a posteriori, descoberto pelos historiadores, é apenas contingente.

Desse modo, os seres humanos, por um lado, devem acreditar no progresso histórico ao interpretar o mundo através da faculdade da razão, ou seja, a partir de sua característica a priori, uma vez que essa é uma necessidade da razão prática e é um requisito para que a moralidade se torne possível. E mesmo que essa crença no progresso pareça não se sustentar ao analisarmos o curso da história de um ponto de vista empírico, devemos mantê-la e interpretar os possíveis declínios como uma aberração temporária do curso geral da história.

Já os historiadores, por outro lado, devem interpretar o mundo mantendo sua crença no progresso como uma teoria empírica que poderia ser falsificada dependendo da verdade de fatos contingenciais. Nessa perspectiva, até mesmo a principal força motriz do progresso, que é natureza humana, seria entendida como algo contingencial e novos dados poderiam, por exemplo, fazer com que as crenças dos historiadores sobre a sociabilidade insociável do homem sejam revisadas.

Essa diferença, por si só, não nos permite concluir que o progresso seja ou não real na história empírica e por isso não pode ser superestimada. E certo que um estudo empírico depende de eventos empíricos e de pensar a natureza humana como algo empírico e contingencial, mas se alguma evidência empírica sustenta a afirmação geral de que estamos em contínuo progresso, mesmo à luz de algumas evidencias contrárias a isso, um historiador pode reter essa afirmação geral e tomá-la como provável. Um exemplo disso é que, apesar das oscilações que se pode perceber ao longo da história (depressões e recessões econômicas), os economistas tendem a insistir que o capitalismo estaria caminhando em direção a um crescimento econômico contínuo. Da mesma forma, o historiador também poderia fazer tal análise e concluir que o progresso da humanidade é real do ponto de vista empírico apesar de nos depararmos com vários contratempos ocasionais.

Um segundo ponto analisado por Rauscher é de que essa derivação do progresso histórico, a partir de uma perspectiva empírica requer um uso a priori da razão, uma vez que ela pressupõe uma ordem e uma unidade na experiência. Se assim for, de fato, talvez não haja uma história puramente empírica. Podemos perceber isso na analogia que Kant faz sobre a órbita dos planetas e o modo como observamos isso. Ele observa 
que o universo necessita de uma estrutura sistemática onde tudo está em perfeita ordem. Essa suposição é baseada na unidade e coerência das leis da natureza, tal como vemos na Arquitetônica da Razão Pura da KrV, quando Kant descreve:

Por arquitetônica entendo a arte dos sistemas. Como a unidade sistemática é o que converte o conhecimento vulgar em ciência, isto é, transforma um simples agregado desses conhecimentos em sistema, a arquitetônica é, pois, a doutrina do que há de científico no nosso conhecimento em geral e pertence, assim, necessariamente, à metodologia (KANT, KrV, A832/ B/860)

Essa ideia de unidade sistemática é comum a todas as ciências, sejam elas físicas ou sociais. Ora, se esse uso de ideias comuns da razão anulasse a afirmação do historiador sobre a ciência empírica, então não poderíamos ter nenhum tipo de ciência empírica, uma vez que toda e qualquer ciência exige ideias comuns da razão para ser considerara como tal. Ou seja, o uso dessas ideias da razão, que supostamente poderia indicar que não existisse nenhum tipo de ciência empírica na história, não torna um conhecimento empírico em si mesmo menos válido do que um conhecimento empírico nas outras ciências.

$\mathrm{O}$ terceiro ponto destacado por Rauscher diz respeito à história como ciência. Ele questiona que se Kant toma a história não apenas para possuir ideias comuns que são compartilhadas por todas as ciências, mas também (e ainda mais) para exigir sua própria ideia, que a distingue das outras ciências como uma ciência singular, então a história empírica exigiria uma ideia da razão e, portanto, não poderia ser considerada estritamente empírica.

No entanto, a $\mathrm{KrV}$ já sustentava que qualquer ciência deveria ser organizada em torno de uma ideia da razão, de modo que possa realizar sua sistemática do conhecimento e manter-se coerente com a unidade da razão.

Se considerarmos em todo o seu âmbito os conhecimentos do nosso entendimento, encontramos que a parte de que a razão propriamente dispõe e procura realizar é a sistemática do conhecimento, isto é, o seu encadeamento a partir de um princípio. Esta unidade da razão pressupõe sempre uma ideia, a da forma de um todo do conhecimento que precede o conhecimento determinado das partes e contém as condições para determinar a priori o lugar de cada parte e sua relação com as outras. Esta ideia postula, por conseguinte, uma unidade perfeita do conhecimento do entendimento, mercê da qual, este não é apenas um agregado acidental, mas um sistema encadeado segundo leis necessárias. Não se pode propriamente dizer que esta ideia seja o conceito de um objeto, mas sim o da unidade completa destes conceitos, na medida em que esta unidade serve de regra ao entendimento. Semelhantes conceitos da razão não são extraídos da natureza (KANT, KrV, A645/ B673, grifo nosso).

Rauscher chama a atenção neste ponto para a interpretação de Pauline Kleingeld, dizendo que, na concepção dela, Kant oferece sua ideia da razão para a história como uma ideia candidato (candidate idea) (Cf. RAUSCHER, 2001, p. 49) e ela observa que Kant deixa aberta a questão de como alguém deve decidir quais ideias são mais úteis (useful) do que outras, insinuando que independente da ideia que acaba sendo utilizada, a história empírica necessitará sempre de uma outra ideia específica para ser considerada uma ciência distinta e, portanto, a história empírica, não poderia ser considerada, de fato, puramente empírica².

Todavia, Rauscher procura contra-argumentar Kleingeld explicando que o fato da história empírica depender de uma ideia (seja uma ideia da razão ou qualquer outro tipo de $i d e i a$ ) não constitui um problema em si e nem pode nos levar à conclusão de que 
a história empírica não seja realmente empírica, uma vez que as ciências devem, de fato, possuir algo que as organiza como ciência.

O que está em jogo aqui é que, primeiramente, esse conceito de organização não necessariamente precisa ser uma ideia da razão. Por exemplo, o entendimento pode fornecer conceitos específicos para uma ciência, como é o caso dos conceitos utilizados na física que dizem respeito à matéria: eles não são derivados da razão, mas derivados do entendimento em conjunto com o conceito empírico da matéria no espaço e tempo (Cf. KANT, MAN, AA 04: 1-12).

Em um segundo momento, precisamos entender que se é necessária uma ideia da razão na história para diferenciá-la como uma ciência distinta das outras, essa exigência valeria também para as outras ciências empíricas, ou seja, essa exigência não deveria valer apenas para a história empírica. Com efeito, se assim fosse, não existiria nenhuma ciência puramente empírica, pois para que uma ciência se constitua como tal, precisa de uma ideia que a organize (seja uma ideia da razão, ou qualquer outro tipo de ideia possível).

O último ponto analisado por Rauscher se concentra na tese do progresso, mais especificamente se esse progresso é real na história empírica. Ele percebe que os conceitos atuais que a história empírica utiliza para poder demonstrar que o progresso é real não podem ser originadas do entendimento, mas, ao contrário, devem ser oriundos da razão. É o caso do argumento da sociabilidade insociável do homem: esse antagonismo leva os seres humanos a fazerem uso da razão para atender às suas necessidades e isso pode ser percebido na história empírica.

Todavia, alguns intérpretes de Kant, como Rudolph Makkreel, veem neste argumento a afirmação de uma perspectiva teleológica, pois envolveria a afirmação de propósitos e objetivos a serem alcançados pelos homens em suas ações. Ora, se assim for, então não existiria uma história empírica, pois, por ser teleológica, seria derivada da razão e conteria em si intencionalidades a priori ${ }^{3}$.

$\mathrm{O}$ que precisamos discutir nesse ponto é se, de fato, a afirmação empírica do progresso na história seria realmente teleológica. O que Rauscher quer nos mostrar é que, se bem entendida, a história requer, sim, uma perspectiva teleológica, mas apenas na medida em que se baseia na existência de um comportamento aparentemente intencional (Cf. RAUSCHER, 2001, p. 50). Uma vez que se admite um comportamento intencional nos homens como, por exemplo, no caso em que se faz uso da razão para satisfazer suas necessidades em meio ao antagonismo que lhe é inerente na vida em sociedade, o historiador empírico pode utilizar o mesmo tipo de modelos mecanicistas que um cientista natural. É o que acontece quando economistas de hoje se baseiam em modelos matemáticos de comportamento de mercado em um conjunto de pressupostos teleológicos: tais modelos de comportamento não são mais teleológicos do que modelos de dinâmica de fluidos em física e química. E o que se pode perceber é que tanto em economia quanto em história, essas suposições teleológicas podem ser consideradas reinvindicações contingentes a serem testadas empiricamente. Desse modo, o historiador pode estudar o comportamento individual dos seres humanos e chegar à conclusão de que tal comportamento corresponde ao que se espera deles diante do antagonismo da sociabilidade insociável.

\section{CONSIDERAÇÕES FINAIS}

Esse artigo teve como objetivo apresentar alguns pressupostos gerais sobre a Filosofia da História e sua relação com a tese do progresso. Vimos, em um primeiro 
momento, que os antecessores de Kant defenderam a perspectiva de uma filosofia da história alinhada à uma vontade divina, ou melhor, a um desígnio providencial (História-Providência); em um segundo momento analisamos os sentidos de história no pensamento de Kant, deixando claro que podemos entender perspectivas diferentes sobre essa disciplina, a saber, uma história filosófica e outra empírica. Enquanto a primeira faz uso de ideias a priori específicas da razão para encontrar significados e padrões no passado da humanidade (Weltgeschichte), a segunda se restringe aos fatos empíricos, sem recorrer a ideias da reflexão filosófica (Historie). Realizar essa distinção foi importante nesse artigo para analisarmos algumas implicações que isso provoca na compreensão sobre a tese do progresso em Kant.

Com esses pontos observados, podemos concluir que o progresso é real não apenas em uma perspectiva histórica filosófica, mas também em uma história empírica, pois as reinvindicações desta possuiriam um status contingente a posteriori e, ao mesmo tempo, apesar das evidências que possam parecer contrárias, ela conseguiria se manter como ciência, uma vez que ela envolveria, necessariamente, ideias comuns da razão (como toda e qualquer ciência empírica deve possuir para ser constituída como tal) e, ainda, exigir algum conceito ou ideia que permitiria a ela fazer afirmações teleológicas sobre as ações dos homens no curso da história.

No entanto, essa conclusão levanta suspeitas acerca da distinção que Kant faz entre uma história filosófica e uma história empírica (por isso Rauscher afirmara logo no início de seu artigo que tal distinção é problemática): tanto uma quanto a outra teriam em comum o fato de utilizarem ideias da razão, fazerem afirmações teleológicas e ambas sustentariam que o progresso é possível no curso da história independentemente dos possíveis declínios que se possa encontrar em seus vários momentos. Esses pontos da argumentação demonstram que a linha que separa a história filosófica e a história empírica está desfocado, embaçado (blurry) e é por isso que Rauscher sugere que, no ensaio IaG, Kant, ao contrastar seu trabalho com o do historiador, deveria ter oferecido suas reflexões não como uma distinção entre os tipos de história, mas, ao contrário, apenas como uma hipótese dentro da história empírica, pois é a única coisa que de fato nos permite concluir da análise desses pontos.

\section{REFERÊNCIAS}

KANT, Immanuel. Gesammelte Schriften. Hrsg.: Bd. 1-22 Preussische Akademie der Wissenschaften, Bd. 23 Deutsche Akademie der Wissenschaften zu Berlin, ab Bd. 24 Akademie der Wissenschaften zu Göttingen. Berlin 1900ss;

KANT, Immanuel. Idee zu einer allgemeinen Geschichte in weltbürgerlicher Absicht. Trad. Rodrigo Novaes e Ricardo R. Terra. São Paulo: Martins Fontes, 2016. (AA 08);

KANT, Immanuel. Kritik der reinen Vernunft. Trad. de Manuela Pinto dos Santos, $5^{\text {a }}$ Edição. Lisboa: Fundação Calouste Gulbenkian, 2001. (A 1781, B 1789);

KANT, Immanuel. Metaphysische Anfangsgründe der Naturwissenschaften. Trad. Artur Morão. Lisboa: Edições 70, 1990. (AA 04);

DOSSE, François. A História. Trad. Roberto Leal Ferreira. São Paulo: Editora Unesp, 2012;

KLEIN, Joel Tiago. Kant e a Ideia de uma história universal. São Paulo: Edições Loyola, 2016;

KLEINGELD, Pauline. Fortschritt und Vernunft: Zur Geschichtsphilosophie Kants. Würzburg: Köningshausen \& Neumann, 1995;

MAKKREEL, Rudolph. Imagination and Interpretation in Kant. Chicago: University of Chicago Press, 1990

RAUSCHER, Frederick. Kant in Brazil, Frederick Rauscher and Daniel Omar Perez, eds., In Series North American Kant Society Studies in Philosophy, Rochester, NY: Rochester University Press, 2012. Anthology of recent Portuguese language work on Kant 
translated into English;

RAUSCHER, Frederick. The Nature of 'Wholly Empirical' History. In Kant und die Berliner Aufklärung: Akten des IX Internationalen Kant-Kongresses, Band 4, hrsg. Volker Gerhardt, Rolf-Peter Horstmann, und Ralph Schumacher (Berlin: Walter de Gruyter, 2001), 44-51;

128 WALSH, W. H. Introdução à Filosofia da História. Trad. Waltensir Dutra. Rio de Janeiro: Zahar Editores, 1978;

\section{NoTAS}

1 Cf. RAUSCHER, 2001, p. 45.

2 Kleingeld afirma em seu texto Fortschritt und Vernunft: Zur Geschichtsphilosophie Kants (1995, p. 115) que apesar da concordância que Kant alegou ter entre a história empírica e a história filosófica, trabalhada na IaG, ele não nos revela toda verdade sobre isso, mas apenas sua utilidade. O ponto negativo desta alegação é que ela demonstra a impossibilidade tanto de provar, quanto de refutar, que exista uma ideia da razão atuando como um guia (einen Leitfaden) na história. Neste sentido, o texto da IaG nos deixa com a impressão de que Kant está apenas procurando uma confirmação da história como ciência por aproximação desta ideia reguladora da razão e nem mesmo estaria considerando os possíveis pontos conflitantes que ela pressupõe.

3 Rudolph Makkreel exclui tacitamente a história empírica contrastando com uma história "dogmática" (a priori e não-empírica) que possui duas formas de história teleológica, negando que pode haver qualquer "conhecimento constitutivo da intencionalidade histórica", rejeitando a história empírica porque a intencionalidade requer teleologia. (Cf. MAKKREEL, Rudolph. Imagination and Interpretation in Kant. Chicago: University of Chicago Press, 1990, p. 148). 